\title{
Increasing flood risk under climate change: a pan-European assessment of the benefits of four adaptation strategies
}

\author{
Lorenzo Alfieri $^{1}$ (D) $\cdot$ Luc Feyen $^{1} \cdot$ Giuliano Di Baldassarre $^{2}$
}

Received: 28 September 2015 / Accepted: 21 February 2016/Published online: 8 March 2016

(C) The Author(s) 2016. This article is published with open access at Springerlink.com

\begin{abstract}
Future flood risk in Europe is likely to increase due to a combination of climatic and socio-economic drivers. Effective adaptation strategies need to be implemented to limit the impact of river flooding on population and assets. This research builds upon a recently developed flood risk assessment framework at European scale to explore the benefits of adaptation against extreme floods. The effect of implementing four different adaptation measures is simulated in the modeling framework. Measures include the rise of flood protections, reduction of the peak flows through water retention, reduction of vulnerability and relocation to safer areas. Their sensitivity is assessed in several configurations under a high-end global warming scenario over the time range 1976-2100. Results suggest that the future increase in expected damage and population affected by river floods can be compensated through different configurations of adaptation measures. The adaptation efforts should favor measures targeted at reducing the impacts of floods, rather than trying to avoid them. Conversely, adaptation plans only based on rising flood protections have the effect of reducing the frequency of small floods and exposing the society to less-frequent but catastrophic floods and potentially long recovery processes.
\end{abstract}

\section{Introduction}

Recent research provides a considerable body of evidence on the effect of anthropogenic greenhouse gas emissions on the Earth's climate (Stocker et al. 2013). Despite the inevitable uncertainty affecting climatic projections, an increasing number of scientific studies suggest

Electronic supplementary material The online version of this article (doi:10.1007/s10584-016-1641-1) contains supplementary material, which is available to authorized users.

Lorenzo Alfieri

lorenzo.alfieri@jrc.ec.europa.eu

1 European Commission - Joint Research Centre, TP 122, Via E. Fermi 2749, 21027 Ispra (VA), Italy

2 Department of Earth Sciences, Uppsala University, Uppsala, Sweden 
that global warming will exceed $2{ }^{\circ} \mathrm{C}$ and range up to $6{ }^{\circ} \mathrm{C}$ by the end of the century (Betts et al. 2011; Friedlingstein et al. 2014), following Representative Concentration Pathways (RCP) with radiative forcing up to $8.5 \mathrm{~W} / \mathrm{m}^{2}$. In Europe, such a scenario is likely to be linked to a sharp increase in flood risk (Feyen et al. 2012; Alfieri et al. 2015b), making adaptation plans a vital component of current and future disaster risk reduction strategies (Adger et al. 2005; Brandimarte et al. 2009). Flood risk reduction is tackled through structural and nonstructural measures involving flood zoning, land-use planning and private precautionary measures, with notable differences in the approach from country to country, even within Europe (Kreibich et al. 2015).

While the number of coordinated flood reduction plans is steadily growing, particularly at community level (e.g., Stahre 2008; Reinhardt et al. 2011), most flood risk prevention actions performed in the past decades focused on corrective rather than preventive measures. After a flood had hit, a recurrent case of flood management was to reinforce and rise flood protections up to a level that would safely confine the peak flow of the river in case a similar event occurred again in the future (see e.g., Fenn et al. 2014). Yet, more and more research studies based on past events acknowledge dykes heightening as measures of last resort or even examples of maladaptation (Hallegatte 2009; Zurich 2014; Wenger 2015), as they give a misleading impression of complete safety which is at odds with the catastrophic consequences in case of failure during flood events (e.g., Di Baldassarre et al. 2015). The last two decades have seen a progressive policy shift towards programs to give "room for rivers" (Rohde et al. 2006; Opperman et al. 2009), aimed to increase the storage space of rivers by restoring floodplains and thus reducing the flood depth by spreading floodwaters over wider areas. Other adaptation options such as relocation to safer areas or flood proofing of buildings require deeper commitment of homeowners and have thus found limited applications in practice (McLeman and Smit 2006; Bichard and Kazmierczak 2012). Yet, insurance programs and disaster financing schemes have large potential in steering the flood risk management in the private and public sectors (Keskitalo et al. 2014; Jongman et al. 2014).

Quantifying the benefits of adaptation measures is crucial for planning nation-wide coordinated actions for flood risk reduction in view of future socio-economic dynamics and the potential intensification of the hydrological cycle and of its extremes (Alfieri et al. 2015a). Current and past research has described extensively the damage reduction potential of a wide range of adaptation options (ABI 2003; Arnbjerg-Nielsen and Fleischer 2009; Kreibich et al. 2011; Woodward et al. 2011). However, only few studies have quantified the benefits of adaptation strategies through simulation approaches, especially in view of future climate change. Among these, Poussin et al. (2012) used a modelling framework to investigate the benefits of spatial zoning, wet and dry flood-proofing on the future flood risk in the Meuse River. At European level, Rojas et al. (2013) and Jongman et al. (2014) used an ensemble of regional climate projections to assess the sensitivity of increased flood protection standards and of risk transfer financing on riverine flood risk throughout the XXI century.

This work relies on the new flood risk assessment framework proposed by Alfieri et al. (2015b) to illustrate the benefits of adaptation in reducing expected damages and population affected by river floods in Europe under $4{ }^{\circ} \mathrm{C}$ global warming by the end of the century. Adaptation is here intended as of the Intergovernmental Panel on Climate Change (IPCC) terminology (IPCC 2001), hence measures aimed at reducing the sources or enhance the sinks of greenhouse gases, i.e., classified as "mitigation" measures, are not considered in this work. The risk assessment framework comprises hydrological modelling, threshold-based evaluation 
of extreme event magnitude and frequency, fully integrated 2D flood hazard mapping, updated exposure maps, country-specific depth-damage functions and improved vulnerability information to estimate current and future flood risk. Within this framework, we consider four different adaptation options and evaluate their effectiveness in risk reduction. Each adaptation option is therefore simulated in 8 to 12 different configurations to assess the sensitivity of its implementation on the resulting flood risk. Risk reduction estimates are obtained by aggregating the results of seven ensemble simulations in space, over 28 European countries, and in time, through three 30-year time slices (TS), to strengthen the robustness of the analysis.

\section{Data and methods}

The simulation framework for flood risk assessment used in this work is described by Alfieri et al. (2015b). The reader is referred to it for detailed information on the main input data, simulation models, limits of validity and methods used to estimate the future flood risk in Europe under high-end climate scenario, assuming no adaptation measures. Main steps of the risk assessment framework include:

- Continuous daily streamflow simulations from 1976 to 2100 (Alfieri et al. 2015a), forcing a distributed hydrological model (Lisflood, van der Knijff et al. 2010) with an ensemble of seven EURO-CORDEX (Jacob et al. 2014) RCP 8.5 downscaled regional climate scenarios over Europe. The General Circulation Models (GCM) driving the regional models chosen are rated in the top $25 \%$, according to a performance evaluation of CMIP5 models carried out by Perez et al. (2014), in their ability to reproduce spatial patterns and climate variability over the north-east Atlantic region, that is the most influential on the European weather patterns.

- Estimation of potential population affected (PA) and expected damage (ED) of river floods in Europe in the current climate, through a combination of hydrological and high-resolution $(100 \mathrm{~m})$ hydraulic modeling. Output flood extent and depths are coupled with an impact model based on population density and depth-damage relations to estimate PA and ED for selected return periods.

- Each flow peak of the future streamflow scenario exceeding the local flood protection levels is assigned an impact (PA and ED) through linear interpolation among the return periods estimated for the current climate.

- The contribution of the future socio-economic development foreseen at country level is added through a set of 5-year multipliers provided by the Organisation for Economic Cooperation and Development (OECD). Data and related description can be found at the link https://ntcat.iiasa.ac.at/SspDb/dsd.

This work takes future socio-economic developments based on SSP5 (O’Neill et al. 2014), consistent with high mitigation challenges due to high-end warming and willingness to take adaptation measures against climate impacts. SSP5 assumes a world with rapid economic growth as opposed to relatively small changes in population (van Vuuren and Carter 2014).

It is worth noting that the average impact estimates for the baseline period are quantitatively in agreement with reported figures at European level (see Alfieri et al. 2015b), thus supporting the suitability of the impact model and the underlying datasets for future climate projections. 


\subsection{Adaptation measures for flood risk reduction}

Four types of adaptation measures were considered and implemented to different extents, to assess their sensitivity to the corresponding risk reduction. Each adaptation option targets the reduction of flood risk by acting on one of the three components of the risk formula, namely hazard, exposure and vulnerability. In the figures and the related discussions, multiplicative and reduction rates associated to each adaptation option defined below are referred to as "sensitivity factors".

\subsubsection{Increase of flood protection levels}

It aims at reducing the vulnerability of people and assets to extreme streamflow conditions. It requires limited space as it normally consists of elevating the river banks, through permanent or temporary barriers, to increase the maximum streamflow that the watercourse can fully contain and convey downstream without causing damage. This keeps the flood storage to minimum levels hence the magnitude of the flood peak can remain unchanged for long river reaches. As a consequence, its implementation (and maintenance) need be homogeneous within each river basin as local weaknesses would represent preferential triggering points for flooding. In the simulation framework, the return period of current flood protections in Europe, expressed in years, was increased by a set of 12 constant rates ranging between $5 \%$ and $2500 \%$, where the upper bound was derived by the findings of the post-event adaptation scenario, described in Sect. 3.1.

\subsubsection{Reduction of the peak flows}

This adaptation option aims at reducing the flood hazard through a reduction and a delaying of peak flows during extreme events. Peak reduction is achieved by setting up areas within or aside the river network that can be flooded in a controlled manner when the river stage reaches critical levels. In addition, peak flows are reduced by reservoirs, sustainable urban drainage systems (SUDS, e.g., Pasche et al. 2008), retarding basins, infiltration basins, and through targeted land management plans such as afforestation and river renaturation (Reinhardt et al. 2011). In this study, we run the impact model with a set of 11 different reduction factors between $5 \%$ and $95 \%$ applied to the return period (i.e., the average recurrence interval) of simulated discharge peaks.

\subsubsection{Reduction of vulnerability}

It includes all adaptation options which can be modelled through a progressive reduction of the vulnerability, including the implementation of early warning systems, dry and wet flood proofing, and floating buildings, among others (see Strangfeld and Stopp 2014; Kreibich et al. 2015; Pappenberger et al. 2015). In the impact model, the adaptive measure is implemented through a multiplicative factor, ranging between 0 and 1, applied to the damage curves and to the population density layer. One should note that this measure does not reduce the frequency of flooding events but rather the consequences of the flooding, hence the reduction in population affected is to be seen as a reduction of the degree of disruption to the population and their activities. 


\subsubsection{Relocation}

It reduces the exposure of people and assets at risk of flooding by moving them to areas with negligible risk (King et al. 2014). In this adaptation option, some assumptions are taken to identify areas where the relocation would occur. Past events showed that flood relocation is primarily driven by economic evaluations and mostly occurs after catastrophic events which makes the reconstruction costs of the same magnitude of buying a new property (Kick et al. 2011; López-Carr and Marter-Kenyon 2015). The relocation mask was defined as the set of areas with 3 or more meters of flood depth following an event with return period of 20 years, assuming no flood protections in place. By definition, in these areas, flooding has a $50 \%$ probability to occur in a 13.5 year period, so it is likely to be experienced by permanent residents once or more in their lifetime. In addition, on European average, $3 \mathrm{~m}$ correspond to roughly $75 \%$ of the maximum potential flood damage for several land use classes including residential, commerce and industrial, among others (Huizinga 2007). One can note that the criteria defining the relocation mask are independent of the local exposure and vulnerability, thus suggesting the following two considerations: 1) this measure leads to higher benefits in countries with considerable developments along rivers and potentially large flood depths, while little risk reduction can be achieved in wide flood plains where the flooding rarely reaches high depths. 2) The relocation mask is evaluated independently of the local flood protection standards, as a failure in the protections would likely induce a very large impact and a difficult recovery process. In the impact assessment, we tested 8 different relocation ratios between $5 \%$ and $100 \%$, to be applied as multiplicative factors to people and assets located within the area defined by the relocation mask. These modified exposure layers are then used within the risk assessment framework to estimate the impact of future flood peaks and their corresponding inundation depths.

\section{Results}

\subsection{Post-event adaptation}

Before evaluating the four adaptation options we first appraise the flood risk throughout this century when flood protection is incrementally increased after every event with peak flow exceeding the existing protections. We refer to this as post-event adaptation and it is hereby modeled by setting post-event protections to match the return period of the flood flow of the event occurred. Ensemble estimates of expected damage and population affected for the postevent adaptation and no-adaptation scenario are presented in Fig. 1, aggregated over the considered European domain. In the early 2000s impact estimates of the two cases mostly overlap. Flood protections steadily increase in the adaptation case following each damaging event, reaching a European average exceeding 2500 years by the end of the century, as opposed to about 100 years at the start of simulations in 2006. In some simulations, country-average protections rose above 5000 years before year 2020. Note that return period estimates are bound to 10,000 years to avoid instability issues in the upper tail of the extreme value distributions, as each of those is derived from a set of 30 annual streamflow maxima. The benefits of adaptation are more evident in the second half of the century (see Figures S1 and S2 of the Supplement). Population affected every year in Europe by river floods drops from 660,000 to 330,000 in 2050 s and from $1,000,000$ to 440,000 in 2080 , in case post-event 
Fig. 1 Annual estimates of population affected and expected damage in Europe in case of noadaptation (grey) and post-event adaptation (red). Ensemble spread (shaded colors) and mean value (solid line). The bottom panel shows the projected temporal evolution of the return period of flood protections
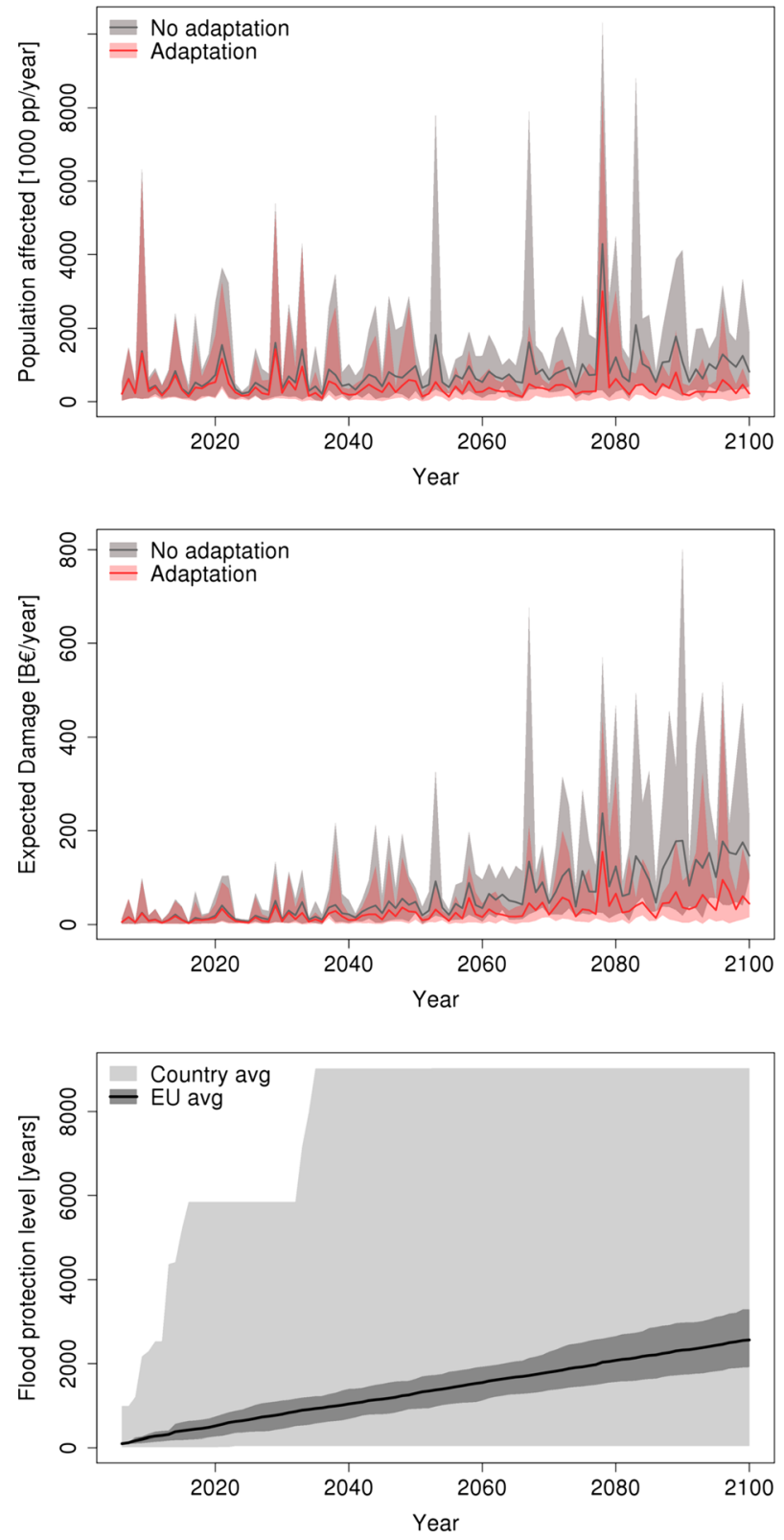

adaptation measures are taken. Accordingly, expected damage is reduced from 41 to $21 \mathrm{~B}$ $€ /$ year in 2050 and from 105 to $42 \mathrm{~B} € /$ year in 2080s. At country level, average risk reduction rates are within 30 and $73 \%$, the lowest values being for the Netherlands, where the initial protection levels are the highest among the considered countries (see Table S1 of the Supplement). It should be noted that this work focuses on direct damage only. Indirect losses are often assumed to be about $40 \%$ of the direct ones, but they might actually become much 
larger if unexpected chains of events take place, such as during the 2011 Thailand flooding (Haraguchi and Lall 2014).

\subsection{Sensitivity analysis of adaptation strategies}

The effect of the four adaptation strategies described in Sect. 2.1 on annual estimates of population affected and expected damage in Europe is shown in Fig. 2. The ensemble range of three 30-year time slices centered in year 2020, 2050 and 2080 is shown with color shades, together with their ensemble mean with a solid line. Each graph includes the corresponding average impact of the same set of simulations over the baseline window 1976-2005. Graphs in Fig. 2 clearly indicate increasing flood risk and ensemble spread for time slices further in time, as a combination of increasing hazard due to climatic change and of socio-economic drivers. The effect of the latter is visibly more pronounced on the expected damage (Fig. 2, right column), resulting from a larger growth of the economy as compared to that of population, as projected in the SSP5. Graphs in Fig. 2 indicate a non-linear behavior in the risk reduction of the first two adaptation options, as opposed to a linear trend in the latter two, which leave the flood depth and extent unchanged while acting on measures to reduce the disruption to population and assets. Past levels of flood impact are unlikely to be retained by the end of the century if only one adaptation option is implemented.

Risk reduction estimates were then aggregated for each of the 28 countries and of the three future time slices. Figures 3 and 4 show the results for Germany, France, UK and Italy, which together contribute to more than $50 \%$ of the European population considered in this study. Graphs of 24 more countries are available in the Supplement material (Figures S3 and S4). Each graph shows, with a horizontal dashed line, the risk reduction $\left(\mathrm{RR}_{\mathrm{b}}\right)$ needed to retain the relative flood impact of the baseline window 1976-2005. Differently from Fig. 2, the horizontal line referring to historical impact data do not include the socio-economic development but only the effect of climate change. In practice, it represents the risk reduction needed to keep the historical ratio of population affected and economic damage as compared to the country population and GDP. In most countries, $\mathrm{RR}_{\mathrm{b}}$ grows in time due to the increasing flood risk, which implies a continuous effort to improve the adaptation strategy. For instance, in Germany (DE) in the TS 2020, historical values of flood impact can be retained as long as adaptation measures are implemented to achieve a risk reduction of $65 \%$ (PA, Fig. 3) and $61 \%$ (ED, Fig. 4), as compared to the no-adaptation scenario. Regarding population affected, the risk reduction can be achieved on average with $65 \%$ reduction of vulnerability, $80 \%$ reduction of the return period of peak flows, or a 5 to 10 -fold increase in the return period of flood protections. One can note that a complete relocation of people living in the relocation mask would reduce the population affected by only $12 \%$ (see Table S2 in the Supplement), which is far less than the target risk reduction. On the other hand, the reduction in expected damage through relocation was always found larger (e.g., $59 \%$ in Germany), suggesting that a considerable proportion of assets is currently located in areas at risk of flooding. Summary statistics for the other countries can be found in Table S2 and Figure S5 in the Supplement material. Also, it is noteworthy that vulnerability reduction measures do not depend on the climate scenarios and consequently on the frequency of flooding, hence no spread of the climate scenarios can be seen in Figs. 3 and 4.

Lastly, Fig. 5 relates the risk reduction of each adaptation measure with the corresponding distribution of the simulated annual relative impact of floods per country through years 20062100. For each measure, the shaded area encompasses all positive annual impacts from seven 

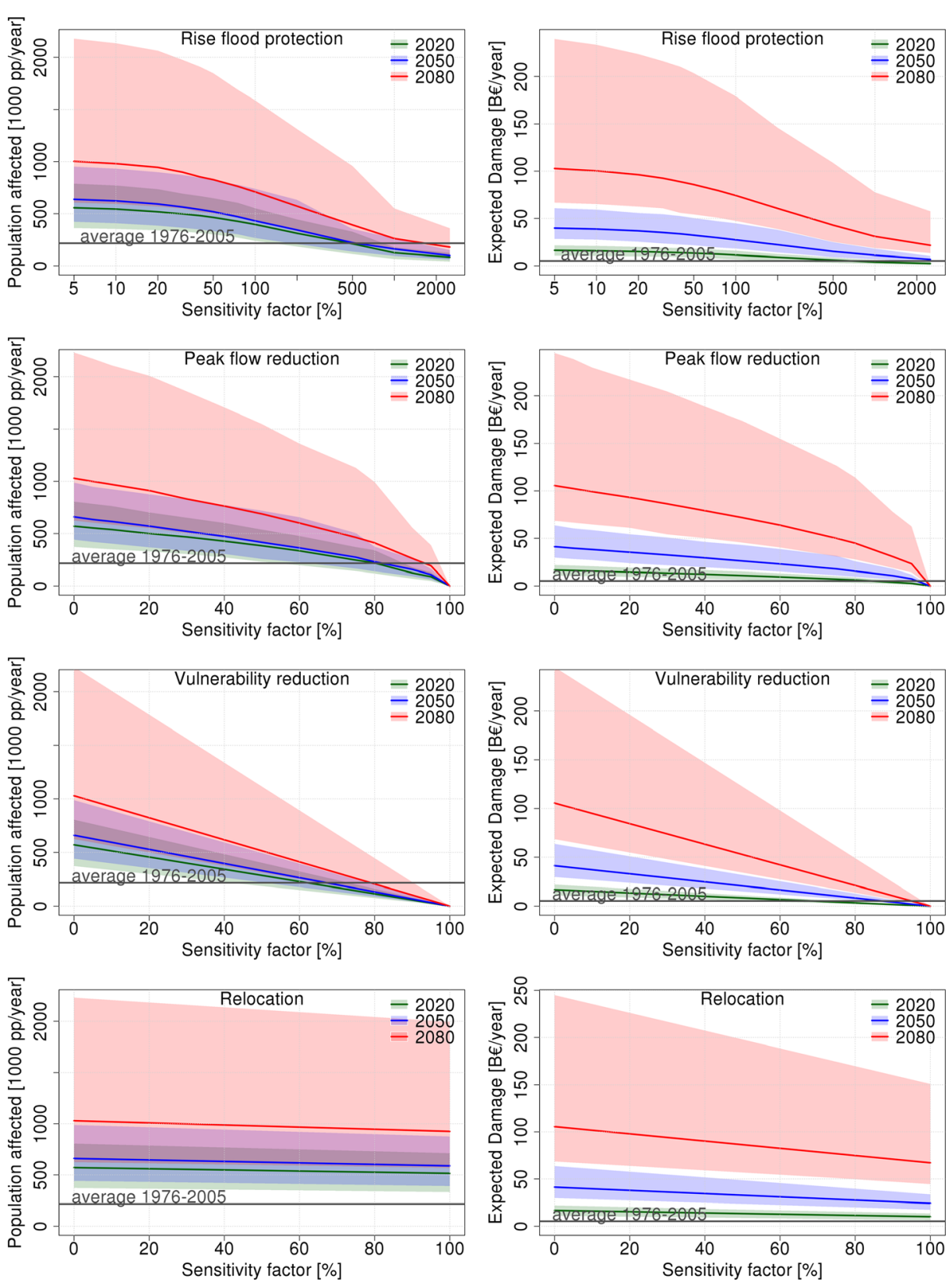

Fig. 2 Benefits of four adaptation strategies on ensemble annual estimates of population affected (left) and expected damage (right) in Europe in time slice 2020, 2050 and 2080

ensemble simulations, while the mean impact is shown with a solid line. In other words, the figure highlights the risk reduction of different adaptation measures on extreme flood years, for different rates of long-term risk reduction. Germany, France, UK and Italy are shown in Fig. 5, while all the other countries are included in the Supplement material (Figure S6 and S7). In Fig. 5, the first two adaptation measures give similar results, as they are both focused on 

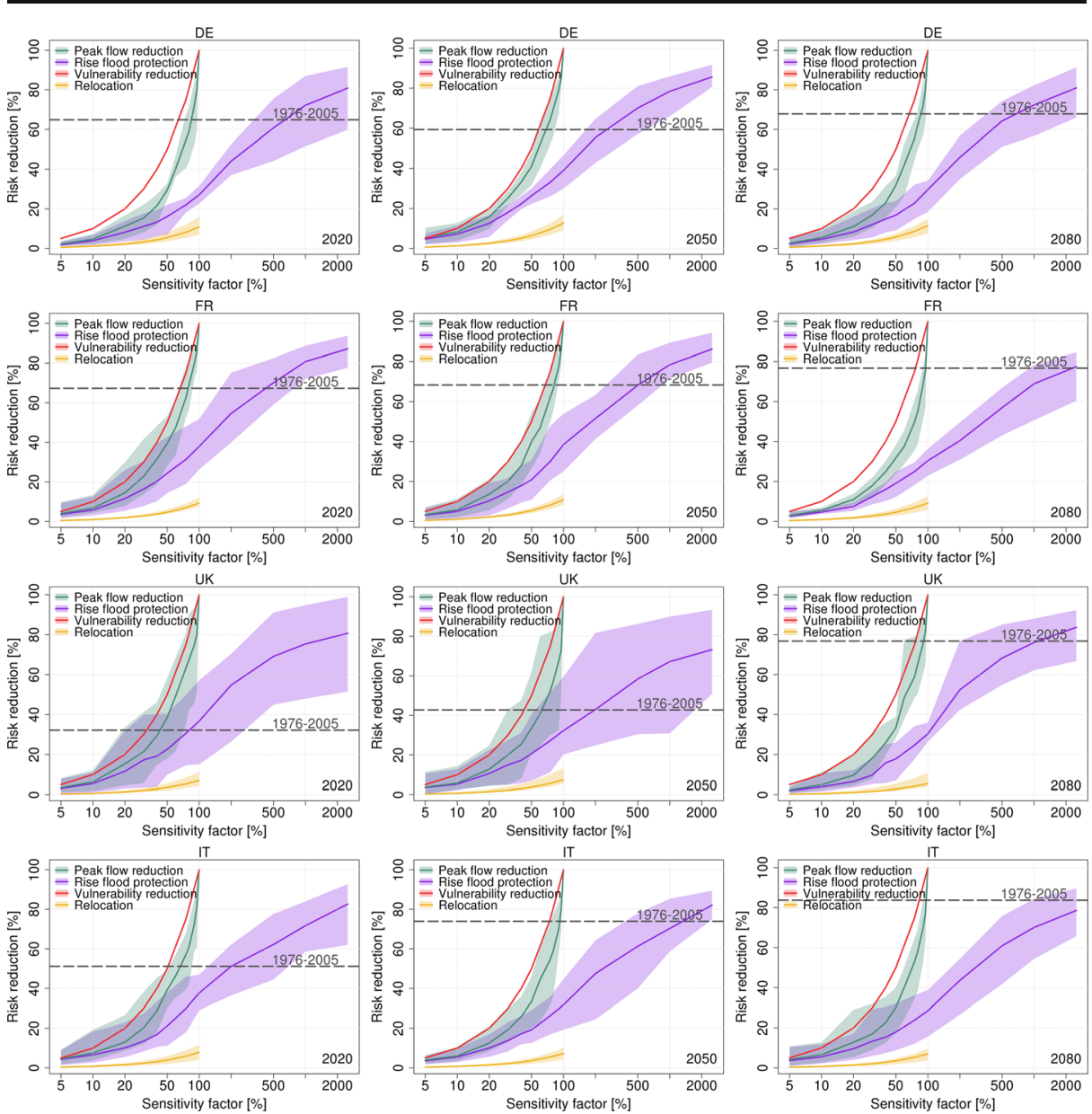

Fig. 3 Risk reduction in population affected through different adaptation options. Ensemble projections over 3 time slices are shown for Germany, France, UK and Italy

reducing the flood threshold exceedances by either reducing the peak flow or by rising the flood protection level. Relative impact values tend to remain high suggesting that the risk reduction is achieved mostly through a reduction of the frequency of minor events, while catastrophic events retain a relatively large impact. On the other hand, vulnerability reduction and relocation often show a linear trend decreasing fast with risk reduction, as they reduce the impact of all events. In Germany, $40 \%$ average reduction on the expected damage through relocation would lead to a worst case scenario with potential annual damages up to $0.7 \%$ of the country GDP. Instead, if the same average risk reduction is obtained by implementing peak flow reduction or rising flood protections, extreme flood years could yield impacts up to $1.4 \%$ of German GDP and $2.4 \%$ of its population. Similarly, smaller countries have higher chance of being hit by widespread floods affecting their entire area, with differences in potential impact sometimes above $5 \%$ of their GDP and population, depending on the chosen adaptation option, such as in the case of Croatia and the Netherlands for the population affected, and Austria and Republic of Macedonia for the expected damage (see Supplement material). 

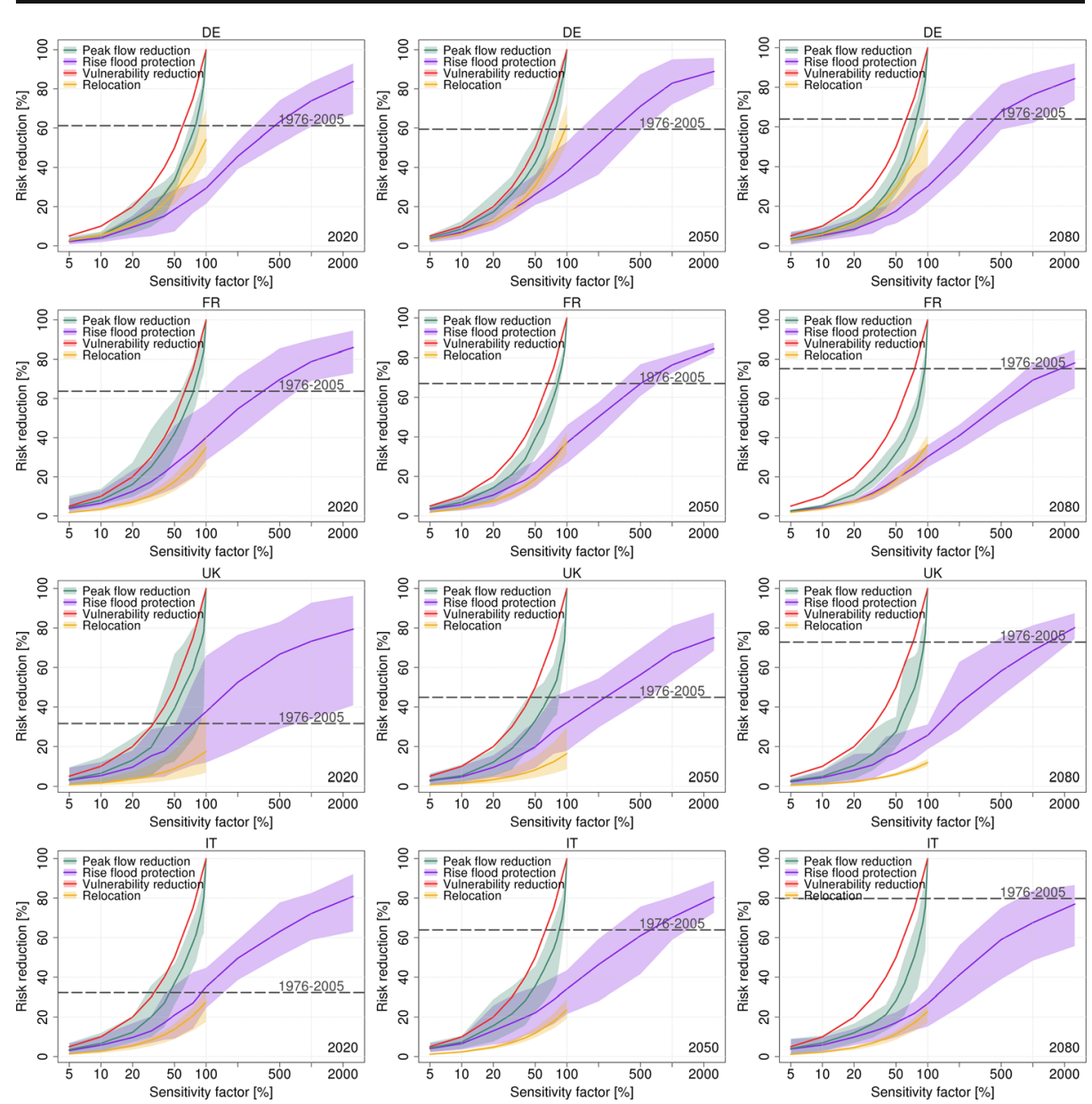

Fig. 4 Risk reduction in expected damage through different adaptation options. Ensemble projections over 3 time slices are shown for Germany, France, UK and Italy

\section{Discussion}

The results and applicability of the proposed adaptation measures should be considered in light of their inherent assumptions and limitations. Sensitivity factors approaching $100 \%$ reduction of the peak flow and of the vulnerability (Fig. 2 to Fig. 4) are unrealistic with technologies currently available. Simulations in the upper range of sensitivity are shown for completeness of the analysis as well as to show the effect of the climate uncertainty at different sensitivity levels. In real world applications, peak flow reduction rates rarely exceed $50 \%$ (Pasche et al. 2008; Reinhardt et al. 2011) and tend to decrease with the event magnitude and with the catchment area. With regard to vulnerability reduction, early warning systems are known to yield profitable cost-benefit ratios (Pappenberger et al. 2015), though with relatively low risk reduction ratios (Meyer et al. 2012). On the other hand, structural measures for vulnerability reduction lead to higher risk reduction rates, at the expense of more considerable investments. 

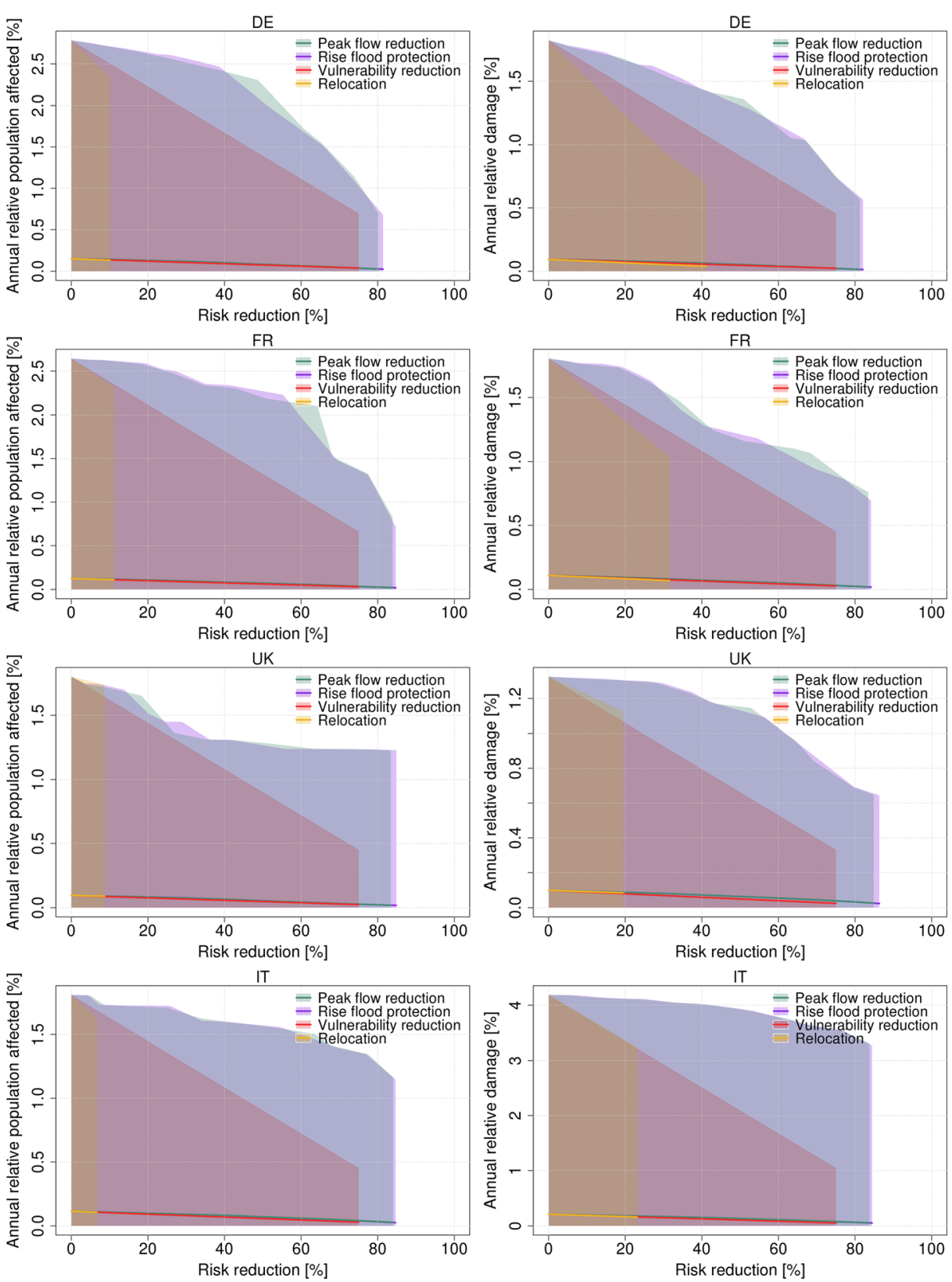

Fig. 5 Relative annual flood impact expressed as population affected (left) and expected damage (right) for different risk reduction factors. Graphs show country aggregated data for Germany, France, UK and Italy

From a numerical viewpoint, it appears that rising flood protections is the only adaptation option that can compensate for any increase in the flood risk. It has relatively high costeffectiveness (Fenn et al. 2014) and often finds little societal resistance in its implementation as it is mostly not associated with land-use changes. However, a comprehensive analysis of costs 
and benefits of this adaptation measure should include the following issues, which are currently not implemented in this simulation framework and are sometimes ignored in practical applications:

- An additional risk component is due to the probability of failure of the flood protections for event magnitudes lower than the design standards, as often occurs in flood events (Apel et al. 2006; Serre et al. 2008; Zurich 2014).

- Heightening river dykes reduces the probability of overflowing thus minimizing the floodplain storage and increasing the magnitude of peak flows downstream.

- Rising flood protections and the consequent reduction in the frequency of flooding events favors the loss of flood memory, leading to increasing exposure in flood-prone areas ( $\mathrm{Di}$ Baldassarre et al. 2015). This dynamic, usually referred to as "levee effect", is characterized by potentially long flood-free periods followed by catastrophic events and large flood losses.

The latter point is supported by the results in Fig. 5 showing how, for fixed risk reduction values, rising flood protections lead to larger socio-economic impacts than in the case of relocation and vulnerability reduction. Past research has shown that the difficulty and the time of recovery of population and ecosystems increase more than linearly with the relative impact of events (Romme et al. 1998; Me-Bar and Valdez 2004), leading the system to a complete collapse in case of extreme disasters. In this regard, the European Union Solidarity Fund (EUSF) was set up to support EU member states significantly affected by disasters, to help and speed up the recovery process. However, Jongman et al. (2014) suggested that the expansion of the EUSF budget to compensate for future large scale floods is infeasible with the projected increasing trend in flood losses for the current century. In addition, such compensation mechanism might be a disincentive for governments to undertake active risk reduction efforts. On the other hand, empirical evidence suggests that recurrent flooding is usually associated with decreasing vulnerability (e.g., Wind et al. 1999; Kreibich and Thieken 2009; Jongman et al. 2015), due to the enhanced resilience and coping capacity acquired by the society during previous events (so-called "adaptation effect").

A final comment is devoted to the uncertainty of climate projections and their impact on adaptation. The benefits of methods relying on reducing the exceedance of flood thresholds (i.e., rising flood protections, reducing peak flow) heavily depend on the future climate scenario. In some cases, the magnitude of future climate extremes is within a relatively wide range around that of local flood protections, so that the consequent ensemble range of estimated risk reduction can be large. Striking examples are those of the UK, TS 2050 (Fig. 3), with up to $50 \%$ of uncertainty in the risk reduction, and other examples in the Supplement, such as for Belgium (TS 2020), Denmark (TS 2050), Estonia (TS 2020), Hungary (TS 2050), Luxemburg (TS 2080) and Netherlands (TS 2080). Uncertainty in risk reduction consistently decreases in the case of relocation and disappear altogether in vulnerability reduction, as these measures rely on reducing the consequences of a flooding event, rather than trying to avoid it. In addition, despite our effort to characterize and possibly minimize the climatic uncertainty, one should be aware of other sources of uncertainty (e.g., in the hydrological and hydraulic modeling, in the space-time discretization, in the impact model, among others) which affect complex modeling framework such as the one presented in this work. 


\section{Conclusions}

In a $4{ }^{\circ} \mathrm{C}$ global warming scenario, the socio-economic impact of river floods in Europe is likely to triple before the end of the century (Alfieri et al. 2015b). In this work, we implemented a relatively simple model applicable to large areas, which can be used to assess the sensitivity of linear changes in different components of the risk formula, to the overall flood risk under selected climatic scenarios. In comparison to previous similar works, the key feature of this research is the use of a high-resolution modeling framework combined with a large number of simulated scenarios, resulting from the product of four adaptation options, an average of ten rates of implementation of each option, seven regional climate models spanning 125 years of climatic data, and two flood impact indicators. We showed how four different classes of adaptation options can reduce the future flood risk to compensate for the impact of climate change. Research findings suggest that current relative flood impact levels can be retained or even decreased in the future decades, provided that coordinated and effective adaptation plans are promptly prepared and put into action.

Under the projected increase in frequency and magnitude of river floods, traditional approaches based only on rising indefinitely local flood protections are not sustainable in the long term. The combined effect of these two dynamics is likely to exacerbate the "levee effect" by reducing the frequency of moderate events and exposing the society to few catastrophic floods, followed by potentially long and painful post-event recovery. We recommend future adaptation strategies to be based on a combination of different measures working in synergy and optimized at the level of river basins, rather than through independent actions over selected river reaches. In agreement with previous research (Zurich 2014; Di Baldassarre et al. 2015), we have showed that adaptation efforts should give priority to measures targeted at reducing the consequences of hazardous events, rather than trying to avoid their occurrence. In particular, relocation and vulnerability reduction measures should be further developed, due to their two key features of 1) reducing the impacts of all floods without reducing their frequency, thus strengthening the resilience of societies and ultimately the "adaptation effect"; and 2) reducing the effects of uncertainty in future climate on the consequent risk reduction due to adaptation measures. Further adaptation measures to reduce the peak flow should make use of natural retention capacity upstream, while rising flood protections should be seen as last resort, to compensate for the residual risk in areas where other options cannot be implemented. In the latter case, best practice in the realization of new structures include 1) the need for gradual and noncatastrophic failure in case of overload, and 2) building in redundancy, so that a single failure in the system would not compromise the overall flood risk protection capacity.

Acknowledgments The research leading to these results has received funding from the European Union Seventh Framework Programme FP7/2007-2013 under grant agreement no 603864 (HELIX: "High-End cLimate Impacts and eXtremes"; www.helixclimate.eu).

Open Access This article is distributed under the terms of the Creative Commons Attribution 4.0 International License (http://creativecommons.org/licenses/by/4.0/), which permits unrestricted use, distribution, and reproduction in any medium, provided you give appropriate credit to the original author(s) and the source, provide a link to the Creative Commons license, and indicate if changes were made. 


\section{References}

ABI (2003) Assessment of the cost and effect on future claims of installing flood damage resistant measures

Adger WN, Arnell NW, Tompkins EL (2005) Successful adaptation to climate change across scales. Glob Environ Chang 15:77-86. doi:10.1016/j.gloenvcha.2004.12.005

Alfieri L, Burek P, Feyen L, Forzieri G (2015a) Global warming increases the frequency of river floods in Europe. Hydrol Earth Syst Sci 19:2247-2260. doi:10.5194/hess-19-2247-2015

Alfieri L, Feyen L, Dottori F, Bianchi A (2015b) Ensemble flood risk assessment in Europe under high end climate scenarios. Glob Environ Chang 35:199-212. doi:10.1016/j.gloenvcha.2015.09.004

Apel H, Thieken AH, Merz B, Blöschl G (2006) A probabilistic modelling system for assessing flood risks. Nat Hazards 38:79-100. doi:10.1007/s11069-005-8603-7

Arnbjerg-Nielsen K, Fleischer HS (2009) Feasible adaptation strategies for increased risk of flooding in cities due to climate change. Water Sci Technol 60:273-281. doi:10.2166/wst.2009.298

Betts RA, Collins M, Hemming DL, et al. (2011) When could global warming reach 4 C? Philos Trans R Soc A Math Phys Eng Sci 369:67-84

Bichard E, Kazmierczak A (2012) Are homeowners willing to adapt to and mitigate the effects of climate change? Clim Chang 112:633-654. doi:10.1007/s10584-011-0257-8

Brandimarte L, Brath A, Castellarin A, Baldassarre GD (2009) Isla Hispaniola: A trans-boundary flood risk mitigation plan. Phys Chem Earth 34:209-218. doi:10.1016/j.pce.2008.03.002

Di Baldassarre G, Viglione A, Carr G, et al. (2015) Debates - perspectives on sociohydrology: capturing feedbacks between physical and social processes. Water Resour Res 51:4770-4781. doi:10.1002/ 2014WR016416

Fenn T, Fleet D, Hartman M, et al (2014) Study on economic and social benefits of environmental protection and resource efficiency related to the European semester final report

Feyen L, Dankers R, Bódis K, et al (2012) Fluvial flood risk in Europe in present and future climates. Clim Chang 1-16

Friedlingstein P, Andrew RM, Rogelj J, et al. (2014) Persistent growth of CO2 emissions and implications for reaching climate targets. Nat Geosci 7:709-715. doi:10.1038/ngeo2248

Hallegatte S (2009) Strategies to adapt to an uncertain climate change. Glob Environ Chang 19:240-247. doi:10. 1016/j.gloenvcha.2008.12.003

Haraguchi M, Lall U (2014) Flood risks and impacts: A case study of Thailand's floods in 2011 and research questions for supply chain decision making

Huizinga HJ (2007) Flood damage functions for EU member states. HKV Lijn in water, Lelystad, the Netherlands

IPCC (2001) Climate change 2001: synthesis report. A contribution of working groups I, II, and III to the third assessment report of the integovernmental panel on climate change [Watson, R.T. and the Core Writing Team (eds.)]. Cambridge University Press, Cambridge

Jacob D, Petersen J, Eggert B, et al. (2014) EURO-CORDEX: new high-resolution climate change projections for european impact research. Reg Environ Chang 14:563-578. doi:10.1007/s10113-013-0499-2

Jongman B, Hochrainer-Stigler S, Feyen L, et al. (2014) Increasing stress on disaster-risk finance due to large floods. Nat Clim Chang 4:264-268. doi:10.1038/nclimate2124

Jongman B, Winsemius HC, Aerts JCJH, et al. (2015) Declining vulnerability to river floods and the global benefits of adaptation. Proc Natl Acad Sci U S A 112:E2271-E2280. doi:10.1073/pnas.1414439112

Keskitalo ECH, Vulturius G, Scholten P (2014) Adaptation to climate change in the insurance sector: examples from the UK, Germany and the Netherlands. Nat Hazards 71:315-334. doi:10.1007/s11069013-0912-7

Kick EL, Fraser JC, Fulkerson GM, et al. (2011) Repetitive flood victims and acceptance of FEMA mitigation offers: an analysis with community-system policy implications. Disasters 35:510-539. doi:10.1111/j.14677717.2011.01226.x

King D, Bird D, Haynes K, et al. (2014) Voluntary relocation as an adaptation strategy to extreme weather events. Int J Disaster Risk Reduct 8:83-90. doi:10.1016/j.ijdrr.2014.02.006

Kreibich H, Thieken AH (2009) Coping with floods in the city of Dresden, Germany. Nat Hazards 51:423-436. doi:10.1007/s11069-007-9200-8

Kreibich H, Christenberger S, Schwarze R (2011) Economic motivation of households to undertake private precautionary measures against floods. Nat Hazards Earth Syst Sci 11:309-321

Kreibich H, Bubeck P, Van Vliet M, De Moel H (2015) A review of damage-reducing measures to manage fluvial flood risks in a changing climate

López-Carr D, Marter-Kenyon J (2015) Human adaptation: manage climate-induced resettlement. Nature 517: 265-267. doi:10.1038/517265a 
McLeman R, Smit B (2006) Migration as an adaptation to climate change. Clim Chang 76:31-53. doi:10.1007/ s10584-005-9000-7

Me-Bar Y, Valdez F Jr (2004) Recovery time after a disaster and the ancient Maya. J Archaeol Sci 31:1311-1324. doi:10.1016/j.jas.2004.02.012

Meyer V, Priest S, Kuhlicke C (2012) Economic evaluation of structural and non-structural flood risk management measures: examples from the Mulde River. Nat Hazards 62:301-324. doi:10.1007/s11069-011-9997-z

O'Neill BC, Kriegler E, Riahi K, et al. (2014) A new scenario framework for climate change research: the concept of shared socioeconomic pathways. Clim Chang 122:387-400. doi:10.1007/s10584-013-0905-2

Opperman JJ, Galloway GE, Fargione J, et al. (2009) Sustainable floodplains through large-scale reconnection to rivers. Science 326:1487-1488. doi:10.1126/science.1178256

Pappenberger F, Cloke HL, Parker DJ, et al. (2015) The monetary benefit of early flood warnings in Europe. Environ Sci Pol 51:278-291. doi:10.1016/j.envsci.2015.04.016

Pasche E, Manojlovic N, Behzadnia N (2008) Floods in small urban catchments: hydrological sensitivity, risk assessment and efficient integrative strategies of mitigation. In: Proceedings of the 11th International Conference on Urban Drainage, Edinburgh

Perez J, Menendez M, Mendez FJ, Losada IJ (2014) Evaluating the performance of CMIP3 and CMIP5 global climate models over the north-East Atlantic region. Clim Dyn 1-18. doi:10.1007/s00382-014-2078-8

Poussin JK, Bubeck P, Aerts ,HJCJ, Ward PJ (2012) Potential of semi-structural and non-structural adaptation strategies to reduce future flood risk: case study for the meuse. Nat Hazards Earth Syst Sci 12:3455-3471. doi:10.5194/nhess-12-3455-2012

Reinhardt C, Bölscher J, Schulte A, Wenzel R (2011) Decentralised water retention along the river channels in a mesoscale catchment in South-Eastern Germany. Physics and Chemistry of the Earth, Parts A/B/C 36:309318. doi:10.1016/j.pce.2011.01.012

Rohde S, Hostmann M, Peter A, Ewald KC (2006) Room for rivers: An integrative search strategy for floodplain restoration. Landsc Urban Plan 78:50-70. doi:10.1016/j.landurbplan.2005.05.006

Rojas R, Feyen L, Watkiss P (2013) Climate change and river floods in the European Union: socio-economic consequences and the costs and benefits of adaptation. Glob Environ Chang 23:1737-1751. doi:10.1016/j. gloenvcha.2013.08.006

Romme WH, Everham EH, Frelich LE, et al. (1998) Are large, infrequent disturbances qualitatively different from small, frequent disturbances? Ecosystems 1:524-534. doi:10.1007/s100219900048

Serre D, Peyras L, Tourment R, Diab Y (2008) Levee performance assessment methods integrated in a GIS to support planning maintenance actions. J Infrastruct Syst 14:201-213. doi:10.1061/(ASCE)1076-0342(2008) $14: 3(201)$

Stahre P (2008) Blue-green fingerprints in the city of Malmö. Malmö's way towards a sustainable urban drainage. Va syd, Sweden

Stocker TF, Qin D, Plattner G-K, et al (2013) Climate Change 2013. The Physical Science Basis. Working Group I Contribution to the Fifth Assessment Report of the Intergovernmental Panel on Climate Change-Abstract for decision-makers. Groupe d'experts intergouvernemental sur l'evolution du climat/Intergovernmental Panel on Climate Change-IPCC, C/O World Meteorological Organization, 7bis Avenue de la Paix, CP $2300 \mathrm{CH}-1211$ Geneva 2 (Switzerland)

Strangfeld P, Stopp H (2014) Floating houses: An adaptation strategy for flood preparedness in times of global change. WIT Trans Ecol Environ 184:277-286. doi:10.2495/FRIAR140231

van der Knijff JM, Younis J, de Roo APJ (2010) LISFLOOD: A GIS-based distributed model for river basin scale water balance and flood simulation. Int J Geogr Inf Sci 24:189-212

van Vuuren DP, Carter TR (2014) Climate and socio-economic scenarios for climate change research and assessment: reconciling the new with the ol. Clim Chang 122:415-429. doi:10.1007/s10584-013-0974-2

Wenger C (2015) Better use and management of levees: reducing flood risk in a changing climate. Environ Rev 23:240-255. doi:10.1139/er-2014-0060

Wind HG, Nierop TM, De Blois CJ, De Kok JL (1999) Analysis of flood damages from the 1993 and 1995 meuse floods. Water Resour Res 35:3459-3465. doi:10.1029/1999WR900192

Woodward M, Gouldby B, Kapelan Z, et al. (2011) Real options in flood risk management decision making. Journal of Flood Risk Management 4:339-349. doi:10.1111/j.1753-318X.2011.01119.x

Zurich (2014) Risk Nexus, Central European floods 2013: a retrospective 